\title{
O ESTÁGIO SUPERVISIONADO NOS CURSOS DE FORMAÇÃO DE PROFESSORES PARA A EDUCAÇÃO PROFISSIONAL
}

\author{
Marilandi Maria Mascarello Vieira, Josimar de Aparecido Vieira \\ Instituto Federal de Ciência e Tecnologia do Rio Grande do Sul - IFRS, Campus Sertão \\ DOI: 10.15628/rbept.2019.7569xxxx
}

Artigo submetido em out/2018 e aceito em ago/2019

\begin{abstract}
RESUMO
O estágio supervisionado, se bem planejado e conduzido, constitui-se num momento importante de construção de saberes sobre a docência e contribui para a formação docente. $O$ objeto de estudo do presente trabalho é o estágio supervisionado nos cursos de formação de professores para a educação profissional e tem por objetivo explicitar a organização e as principais características dos estágios supervisionados que neles são desenvolvidos. Foi elaborado com base na análise de produções acadêmicas sobre o tema e contém o relato das atividades desenvolvidas no estágio supervisionado que ocorre em dois cursos de formação de professores para os componentes curriculares da área técnica oferecidos no Campus Sertão do Instituto Federal de Educação, Ciência e Tecnologia do Rio Grande do Sul. Aponta as contribuições de Pimenta (2011), Pimenta: Lima (2009), Almeida; Pimenta (2014), Canário (2001), Kulcsar (2012) e Piconez (2012), dentre outros. Os estágios supervisionados nos cursos de formação de professores para a educação profissional não tem se configurado como objeto de estudos acadêmicos ou relatos de experiências e, assim, nesse texto, visando contribuir para a sistematização de estudos sobre o tema, descrevemos a experiência do estágio supervisionado no IFRS - Campus Sertão que demonstra que o desenvolvimento do estágio supervisionado no processo de formação inicial de professores para a educação profissional se traduz como oportunidade para o estudante compreender criticamente o contexto onde irá atuar profissionalmente.
\end{abstract}

Palavras-Chave: Formação de Professores, Educação Profissional, Estágio Supervisionado, Programa Especial de Formação Pedagógica.

\section{THE SUPERVISED INTERNSHIP IN THE TEACHER TRAINING COURSES FOR PROFESSIONAL EDUCATION}

\begin{abstract}
The supervised internship, if well planned and conducted, constitutes an important moment in the construction of knowledge about teaching and contributes to teacher training. The object of study of the present work is the supervised internship in teacher training courses for professional education and aims to make explicit the organization and main characteristics of the supervised internships that are developed in them. It was elaborated based on the analysis of academic productions on the subject and it contains the report of the activities developed in the supervised internship that occurs in two courses of teacher training for the curricular components of the technical area offered in Campus Sertão of the Federal Institute of Education, Science and Technology of Rio Grande do Sul. It points out the contributions of Pimenta (2011), Pimenta: Lima (2009), Almeida; Pimenta (2014), Canário (2001), Kulcsar (2012) and Piconez (2012), among others. That supervised internships in teacher education courses for professional education have not been configured as object of academic studies or reports of experiences and, in this way, in order to contribute to the systematization of studies on the subject, we describe the supervised internship experience in the IFRS - Campus Sertão, which demonstrates that the development of the supervised internship in the process of initial teacher training for professional education translates as an opportunity for the student to critically understand the context in which he / she will work professionally.
\end{abstract}

Keywords: Teacher Training, Professional Education, Supervised Internship, Special Pedagogical Training Program. 


\section{INTRODUÇÃO}

O exercício da docência exige a construção de conhecimentos originários de diferentes fontes, porém a trajetória de formação acadêmica se constitui no momento formal destinado a essa elaboração de saberes e, nesse contexto, o estágio supervisionado tem papel relevante porque permite a aproximação com o contexto de trabalho que apresenta desafios que, por sua vez, contribui para a elaboração dos saberes requeridos pela profissão docente.

O estágio supervisionado nos cursos de licenciatura tem sido objeto de estudos acadêmicos, especialmente enfocando as suas contribuições e formas de organização. Assim, na primeira parte deste trabalho analisamos trinta produções acadêmicas (artigos e trabalhos apresentado em eventos) sobre o tema enfocando os tipos de trabalho, o lócus de produção e as temáticas neles abordadas.

Como resultado dessa busca constatamos a ausência de produções acerca dos estágios supervisionados na formação dos professores para a educação profissional, especialmente nos componentes curriculares das áreas técnicas, razão porque na segunda parte do texto relatamos a experiência do estágio supervisionado desenvolvido nos cursos de Licenciatura em Ciências Agrícolas e no Curso de Formação Pedagógica para Docentes da Educação Básica e Profissional no Campus Sertão do Instituto Federal de Educação, Ciência e Tecnologia do Rio Grande do Sul.

\section{OS ESTÁGIOS SUPERVISIONADOS NA FORMAÇÃO DE PROFESSORES}

Para a produção deste trabalho consideramos necessário mapear a produção acadêmica sobre os estágios supervisionados publicados em revistas e anais de eventos da área educacional, pois esse ponto de partida nos permite vislumbrar o estado do conhecimento sobre o tema.

Assim, procedemos a busca por produções na rede mundial de computadores por meio do google, tomando como referência os descritores "estágio" - "estágio supervisionado" - "licenciatura" - "formação de professores". A razão da escolha do 
google foi por crer que ele permite uma visão geral sobre o tema. Nessa busca localizamos 30 produções - número que consideramos representativo para compor um panorama sobre o tema - sendo 11 artigos e 19 trabalhos completos publicados em anais de eventos diversos. A relação dos trabalhos analisados consta no Quadro 1 (anexo).

Procedemos então a leitura do material identificando o tipo de texto, que organizamos em três categorias: bibliográfico, resultado de pesquisa ou relato de experiências; lócus referenciado na produção, que classificamos em universidades e Institutos Federais de Educação, Ciência e Tecnologia; e temáticas neles abordadas. Não definimos recorte temporal, pois nos interessou identificar o período com maior frequência de produção e constatamos que 4 trabalhos foram publicizados até 2009; 11 entre 2010 - 2014 e 15 no período de 2015 a 2018.

Entretanto, antes de discorrer sobre os resultados desta busca, importa salientar que um dos trabalhos localizados, o de Martins; Nascimento; Souza (2015) apresenta pesquisa do tipo "estado da arte" sobre os estágios supervisionados nas licenciaturas ofertadas pelos IFEs das regiões Norte e Nordeste do Brasil entre 2009 a 2013, cujos trabalhos foram apresentados em cinco edições do Congresso de Pesquisa e Inovação da Rede Norte e Nordeste de Educação Tecnológica (CONNEPI), evento anual promovido pela Rede de Educação Federal de Educação Profissional, Científica e Tecnológica e pela Secretaria de Educação Tecnológica (SETEC) do Ministério da Educação e que, segundo os autores, tem por finalidade a socialização das pesquisas desenvolvidas nos cursos de graduação e pós-graduação daquelas instituições.

Os resultados da investigação de Martins; Nascimento; Souza (2015) indicam baixa produção a respeito do tema, pois, embora na região abrangida pela pesquisa estejam em funcionamento mais de 300 cursos de licenciaturas nos IFEs, os autores localizaram nos Anais dos eventos somente 19 trabalhos originários dos seguintes cursos: 6 da Licenciatura em Ciências Biológicas; 7 da Educação Física; 3 da Matemática; 2 da Química e 1 das Ciências Agrárias. Sobre o tipo de trabalho, os autores classificaram 7 como teóricos e os 12 restantes como relato de experiências.

Chama a atenção, além do número limitado de trabalhos sobre o tema, a inexistência de produções sobre formação de professores para as disciplinas técnicas 
dos cursos de educação profissional, objeto de apenas um trabalho, sendo que os 18 restantes referem-se a licenciaturas "clássicas" ofertadas nas universidades.

Quanto às temáticas abordadas nos trabalhos os autores afirmam que

[...] os artigos publicados abordam o estágio supervisionado como um momento de conhecimento, de reflexão e de grande importância para a formação inicial do professor. Nestes artigos, podem ser observados os limites, as possibilidades, as dificuldades, as surpresas, os desafios, o contentamento e o descontentamento que ocorrem durante 0 estágio. Também são demonstradas as intervenções utilizadas pelos estagiários em sala (MARTINS; NASCIMENTO; SOUZA, 2015, p. 156).

Feita essa remissiva, retomamos os dados da busca por nós realizada e, quanto ao tipo de texto, dos 30 trabalhos que analisamos, 9 classificamos como bibliográficos, 2 como relato de pesquisa e 19 descrevem experiências com estágios supervisionados, produzidos por professores desse componente curricular nos cursos de licenciatura ou graduandos que publicizaram em eventos ou revistas seus trabalhos de conclusão de curso.

Quanto ao lócus, foi possível identificá-los em 21 trabalhos, sendo que 10 foram produzidos nas instituições de ensino superior - universidades - e 11 nos Institutos Federais de Educação, Ciência e Tecnologia (IFEs), dado que chama a atenção, visto que a universidade é o espaço tradicional da formação de professores.

Nos IFs, entretanto, preponderam os trabalhos realizados nas licenciaturas "clássicas" da área das Ciências Naturais: 2 trabalhos abrangeram vários cursos de licenciatura (Matemática/Química/Física/Biologia); 2 enfocam as Ciências Biológicas, 3 referem-se à licenciatura em Química, 1 no curso de Física e somente 1 na área das disciplinas técnicas, a Licenciatura em Computação. Os dados, portanto, não sinalizam cenário distinto do apresentado por Martins; Nascimento; Souza (2015).

Quanto às temáticas abordadas, é recorrente a importância atribuída ao estágio supervisionado na formação dos professores. Tomando como referência os estudos de Pimenta (2011), Pimenta: Lima (2009), Almeida; Pimenta (2014), Canário (2001), Kulcsar (2012) e Piconez (2012), os trabalhos enfocam as contribuições do estágio, considerado como primeira oportunidade de inserção dos licenciandos nas escolas e que contribui em três aspectos: 
a) Na vivência da profissão docente

O estágio supervisionado se constitui num elo entre a formação e o mundo do trabalho que permite ao licenciando inserir-se na realidade da profissão docente porque, segundo Kulcsar (2012, p. 58) ele desencadeia a "[...] relação entre polos de uma mesma realidade e prepara mais convenientemente 0 aluno estagiário para 0 mundo do trabalho, desde que a escola e o trabalho façam parte de uma mesma realidade social e historicamente determinada".

O campo de estágio se constitui num espaço formal que proporciona o contato sistematizado do futuro professor com as atribuições profissionais e é quando inicia a articulação entre os saberes construídos na licenciatura para dar conta dos desafios da prática docente, como ratificam Almeida; Pimenta (2014, p. 73):

\footnotetext{
Durante o curso de graduação começam a ser construídos os saberes, as habilidades, posturas e atitudes que formam 0 profissional. Em períodos de estágio, esses conhecimentos são ressignificados pelo aluno estagiário a partir de suas experiências pessoais em contato direto com o campo de trabalho que, ao longo da vida profissional, vão sendo reconstruídos no exercício da profissão.
}

Assim, há nos trabalhos pesquisados o reconhecimento da importância da vivência dessa etapa no contexto escolar como forma de significar os conhecimentos construídos na graduação tendo por referência as situações concretas de atuação na profissão docente.

b) Para a avaliação da formação recebida no curso de graduação

A imersão do licenciando no campo de estágio o coloca frente a situações de trabalho que não foram experienciadas no processo de formação. $O$ espaço/tempo do trabalho e o da formação universitária têm particularidades que precisam ser vivenciadas e o estágio supervisionado permite essa mobilidade que contribui para o confronto de concepções, ideias, experiências e desafios e culmina na construção de aprendizagens significativas para os envolvidos na tarefa: o licenciando, o professor formador e o professor responsável pelo campo de estágio.

Esse trânsito de experimentações deve articular-se à pesquisa porque suscita questões que levam à reflexão e análise crítica sobre as ações e ajuda a integrar 
essa realidade ao processo de formação, melhorando a sua qualidade, pois como diz Tardif (2002, p. 53),

[...] a prática pode ser vista como um processo de aprendizagem por intermédio do qual os professores retraduzem sua formação e a adaptam à profissão [...]. A experiência provoca, assim, um efeito de retomada crítica (retroalimentação) dos saberes adquiridos antes ou fora da prática profissional.

A reflexão sobre a prática contribui para a avaliação da formação docente, tanto pelos licenciandos, que se autoavaliam em relação às demandas da prática, quanto aos professores formadores, que podem ressignificar seu trabalho a partir dos resultados obtidos pelos licenciandos.

c) Na melhoria da articulação entre a instituição de ensino superior e as escolas

O contato do estagiário com o campo de estágio exige que a instituição formadora acompanhe as atividades que ocorrem na escola, o que proporciona momentos de parceria e partilha de concepções, ideias e experiências educativas entre os sujeitos envolvidos nesse processo. Por meio dele o mundo do trabalho se apresenta tal como é, com suas possibilidades e dificuldades que desafiam a construção de conhecimentos conjuntos e promovem o trabalho coletivo nos cursos de formação de professores.

Outra temática abordada nos trabalhos analisados diz respeito às diferentes concepções sobre o estágio descritas por Pimenta; Lima (2009), que ressaltam três concepções de prática que se materializam nos estágios: a prática como imitação de modelos; a prática como instrumentalização técnica e a articulação entre teoria e prática.

A primeira concepção é do estágio como momento da prática em que se reproduzem os modelos que os licenciandos construíram por meio da observação da atuação de professores em sala de aula. Sem sombra de dúvida, os professores referenciais são fontes de conhecimento e proporcionam a construção de saberes sobre a docência, porém essa concepção apresenta limites porque o licenciando não procede a uma análise crítica da situação vivenciada e nem adapta o modelo 
incorporado às situações concretas e desafios propostos pela prática. Segundo Pimenta; Lima (2009, p. 37) "A prática pela prática e o emprego de técnicas sem a devida reflexão pode reforçar a ilusão de que há uma prática sem teoria ou de uma teoria desvinculada da prática".

O segundo modelo é o da prática como instrumentalização técnica e o estágio é considerado o momento de adquirir e aplicar as técnicas de ensino necessárias para a efetivação do processo ensino-aprendizagem. Segundo Pimenta; Lima (2006, p. 9), "nessa perspectiva, a atividade de estágio fica reduzida à hora da prática, ao como fazer, às técnicas a ser empregadas em sala de aula, ao desenvolvimento de habilidades específicas do manejo de classe, ao preenchimento de fichas de observação, diagramas, fluxogramas".

Por fim, há a concepção de estágio enquanto articulação entre teoria e prática que tem na pesquisa seu eixo norteador e que proporciona a ação-reflexão-ação porque toma a prática como ponto de partida. Assim, Pimenta; Lima (2006, p.14) reportam que

A pesquisa no estágio, como método de formação dos estagiários futuros professores, se traduz pela mobilização de pesquisas que permitam a ampliação e análise dos contextos onde os estágios se realizam. Mas também e, em especial, na possibilidade de os estagiários desenvolverem postura e habilidades de pesquisador a partir das situações de estágio, elaborando projetos que thes permitam ao mesmo tempo compreender e problematizar as situações que observam.

Assim considerado, o estágio supervisionado torna-se um componente curricular que provoca a reflexão e problematização sobre as situações de ensinoaprendizagem que ocorrem em sala de aula.

Relacionado a esse tema, os trabalhos também abordam a relação teoria prática apresentando diferentes concepções, caracterizando-as e apontando suas distinções e complementariedades. Há menção a Tardif (2002), que distingue três concepções de prática: prática enquanto arte; prática enquanto técnica e prática enquanto interação que privilegia o desenvolvimento de uma consciência profundamente social. Também são recorrentes as referências a Pimenta (1995) que discorre sobre os conceitos de prática, teoria e práxis nos cursos de formação de 
professores; a Pimenta; Lima (2006) e Pimenta; Lima (2009) que discutem a formação de professores e pedagogos a partir da relação teoria e prática presente nas atividades de estágio. Por fim, também há alusão aos estudos de Canário (2001) e Formosinho (2001) que trataram do tema.

Retornando aos textos que analisamos, dentre os 30 trabalhos, 17 relatam experiências de estágios supervisionados realizados nos cursos de formação de professores, em sua maioria, produzidos por licenciandos como trabalho de conclusão de curso, mas também são comuns relatos de experiências sobre as formas de organização e características dos estágios nos cursos de formação de professores. A lacuna persiste, porém, em relação aos cursos de formação de professores para os componentes curriculares das áreas técnicas da educação profissional, já que apenas um trabalho (resumo expandido) tratou dessa modalidade de ensino, investigando a percepção dos licenciados da Ciência da Computação acerca da contribuição do estágio supervisionado para a formação profissional. Assim, parece não haver indícios sobre a forma como os IFEs organizam os estágios supervisionados que compõem os cursos de formação de professores para a área técnica, razão pela qual elegemos esse como objeto do presente trabalho, que apresenta o relato da organização e funcionamento dos estágios no Instituto Federal de Educação, Ciência e Tecnologia do Rio Grande do Sul, Campus Sertão.

\section{OS ESTÁGIOS SUPERVISIONADOS NOS CURSOS DE FORMAÇÃO DE PROFESSORES DO IFRS - CAMPUS SERTÃO}

A legislação que criou os IFEs (Lei no 11.892/2008, art. 7ํ, VI, b) atribuiu-lhes a finalidade de oferta de cursos de formação de professores nas modalidades licenciatura e programas de formação pedagógica para bacharéis, tornando-os assim, lócus da formação dos professores prioritariamente na área das ciências naturais e dos componentes curriculares das áreas técnicas. Entretanto, dados de Oliveira; Oliveira (2016, p. 30) demonstram que os cursos de licenciatura na área das Ciências Naturais têm sido priorizados nos IFEs ${ }^{1}$, conforme se pode ver no Quadro 2:

\footnotetext{
${ }^{1}$ Não foram localizados dados acerca da oferta de programas de formação pedagógica para docentes nos IFEs.
} 


\section{Quadro 2: Licenciaturas na Rede Federal de Educação Profissional, Ciência e} Tecnologia - 2014

\begin{tabular}{|c|c|}
\hline Cursos & $\begin{array}{l}\text { Quantidade de campi } \\
\text { com curso }\end{array}$ \\
\hline Artes e Artes Visuais & 04 \\
\hline Biologia ou Ciências Biológicas & 29 \\
\hline Ciências Agrárias & 03 \\
\hline Ciências Agrícolas & 02 \\
\hline Ciências da Natureza & 03 \\
\hline Ciências da Natureza com habilitação em Biologia, Física ou Química & 02 \\
\hline Ciências da Natureza com habilitação em Química ou Química & 36 \\
\hline Ciências Sociais & 03 \\
\hline Dança & 02 \\
\hline Educação do Campo & 04 \\
\hline Educação Básica & 01 \\
\hline Educação Física & 06 \\
\hline Espanhol & 02 \\
\hline Física & 31 \\
\hline Geografia & 08 \\
\hline História & 01 \\
\hline Informática ou Computação & 18 \\
\hline Letras & 13 \\
\hline Matemática & 31 \\
\hline Mecânica & 01 \\
\hline Música & 03 \\
\hline Pedagogia & 07 \\
\hline Teatro & 01 \\
\hline TOTAL & 211 \\
\hline
\end{tabular}

Fonte: Oliveira e Oliveira (2016, p. 30). (Grifos nossos).

Os dados do quadro 2 indicam que nos 211 campi que oferecem cursos de licenciaturas, apenas em $28(13,3 \%)$ há cursos nas áreas técnicas, sendo 10 na informática/computação. Por outro lado, segundo a Sinopse Estatística Educação Básica/2017, dos 117.136 professores com graduação que atuam na Educação Profissional, 75.691 (64, 61\%) são licenciados, enquanto 41.445 (35,39\%) não 
possuem licenciatura. Registre-se que essa ausência de licenciados ocorre entre os professores das disciplinas das áreas técnicas, pois os que atuam nos componentes curriculares da formação propedêutica em geral são licenciados por força da Lei no 9396/96, art. 62.

Nesse sentido, como o Instituto Federal de Educação, Ciência e Tecnologia Campus Sertão oferece cursos de formação dos professores para as áreas técnicas, o tomamos como lócus deste trabalho, onde atuamos como docentes em componentes curriculares dos cursos, inclusive dos estágios supervisionados, área que carece de produção acadêmica. Por isso, na sequência apresentamos a estrutura dos cursos e a organização e principais características dos estágios supervisionados, iniciando por uma breve contextualização do Campus.

\subsection{Breve caracterização do Campus Sertão}

O Campus Sertão está vinculado ao Instituto Federal de Educação, Ciência e Tecnologia do Rio Grande do Sul (IFRS), que integra a Rede Federal de Educação Profissional e Tecnológica, com sede em Bento Gonçalves - RS, criado pela Lei no 11.892/2008, que instituiu os IFEs no país. Ele é composto por dezessete campi, resultando da união de três autarquias federais, dois estabelecimentos vinculados a Universidades Federais, três unidades de ensino técnico federalizadas e nove novos Campi.

O Campus Sertão está situado na região Norte do RS e sua trajetória teve início em 1957, criado como Escola Agrícola de Passo Fundo, passou a ser Ginásio Agrícola (1964), Colégio Agrícola (1968), Escola Agrotécnica Federal (1979) e Campus do IFRS (2008). Assim, a instituição tem experiência na oferta de cursos técnicos, com tradição no Técnico em Agropecuária e, a partir de 2009, de outros cursos (técnicos e superiores) com maior ênfase na área dos recursos naturais. Em 2018, o Campus oferece três cursos técnicos de nível médio, quatro de tecnologia, dois bacharelados, três licenciaturas e um curso de especialização lato sensu em educação.

$\mathrm{Na}$ formação de professores o Campus tem três cursos: Licenciatura em Ciências Agrícolas, Licenciatura em Ciências Biológicas e o Curso de Formação 
Pedagógica de Docentes para a Educação Básica e Profissional, além do curso de especialização lato sensu. Como o objetivo deste texto é discorrer sobre o estágio supervisionado nos cursos destinados à formação de professores para as áreas técnicas, nele abordamos os estágios da Licenciatura em Ciências Agrícolas e do Curso de Formação Pedagógica de Docentes para a Educação Básica e Profissional.

\subsection{O curso e o estágio supervisionado em Ciências Agrícolas}

A Licenciatura em Ciências Agrícolas é destinada à formação de professores para o magistério na área da agricultura e afins, especialmente no ensino técnico de nível médio. No cenário nacional, o curso tem diferentes denominações (Licenciatura em Ciências Agrícolas, Licenciatura em Ciências Agrárias ou do Ambiente). Em 2016 foi ofertado em quinze instituições e está em extinção/extinto em cinco. No Campus Sertão, pelo baixo número de alunos matriculados constatamos que, a exemplo do que ocorre com os cursos de licenciatura em muitas instituições do país, há baixa procura por vagas e o índice de evasão é alto. A tendência é de extinção, embora seja um dos poucos cursos de formação de professores para a EP ofertados pelos IFEs, que têm essa como uma de suas atribuições.

O curso foi criado em 2010 e nele ingressaram nove turmas. É ofertado no turno noturno, presencial e com carga horária de 3.120 horas $^{2}$ a serem integralizadas em oito semestres letivos. Sua matriz curricular contém 416 horas de componentes de formação geral, 720 horas de formação pedagógica, 1384 horas de formação específica nas áreas de Produção Animal, Produção Vegetal, Produção Agroindustrial e Infraestrutura Agrícola, 400 horas de estágios supervisionados e 200 horas de atividades complementares.

O núcleo de formação pedagógica é constituído por quinze componentes curriculares: Filosofia da Educação, Sociologia da Educação, Psicologia da Educação, História da Educação, Antropologia das Sociedades Indígenas e Afrodescendentes, Didática, Pesquisa em Educação, Políticas da Educação, Gestão da Educação, Educação de Jovens e Adultos, Educação e Direitos Humanos,

\footnotetext{
${ }^{2}$ Os Projetos Pedagógicos dos Cursos analisados neste trabalho estão em processo de revisão, determinada pela Resolução $n^{\circ} 2$, de 1\%/07/2015, que definiu diretrizes curriculares nacionais para a formação inicial e continuada de professores da educação básica.
} 
Educação do Campo, Educação Ambiental, Educação Inclusiva e Linguagem Brasileira de Sinais.

Quanto aos estágios supervisionados, as 400 horas são realizadas a partir do $4^{0}$ semestre, organizadas em cinco etapas que envolvem a análise de conjuntura do ensino agrícola, as atividades de observação, monitoria e regência (dois semestres). Conforme constatamos na análise da produção acadêmica relatada na primeira parte deste trabalho, as atividades de observação e regência constituem o estágio supervisionado nas instituições que foram lócus dos 21 trabalhos que envolveram pesquisa e relatos de experiências, estando também presente a monitoria, porém em nenhum deles identificamos a produção de análise de conjuntura.

$\mathrm{Na}$ Licenciatura em Ciências Agrícolas a primeira etapa do Estágio Supervisionado - que se intitula análise de conjuntura - é desenvolvida no $4^{\circ}$ semestre com carga horária de 48 horas e refere-se à produção de um texto sobre a educação profissional e o ensino agrícola no contexto mundial e no Brasil. Trata dos aspectos históricos da educação profissional e agrícola, a educação profissional segundo a Lei de Diretrizes e Bases da Educação Nacional (LDB), a oferta dos cursos e a educação profissional na rede federal e estadual no Rio Grande do Sul, articulando os conteúdos discutidos nas disciplinas pedagógicas, especialmente Sociologia da Educação, História da Educação, Políticas de Educação e Educação do Campo.

No Estágio Supervisionado II, realizado no $5^{\circ}$ semestre com carga horária de 58 horas, é realizado o estudo sobre uma instituição de educação básica enfocando seu contexto histórico, localização, infraestrutura, gestão financeira, pedagógica e de pessoal, setores, cursos ofertados, além do detalhamento da organização e funcionamento de um curso da área agrícola (ensino fundamental ou médio) e o relato das observações realizadas em sala de aula no período mínimo de 24 horas, sendo seis horas em um componente curricular de cada uma das áreas do curso: Produção Animal, Produção Vegetal, Produção Agroindustrial e Infraestrutura Agrícola.

A coleta dos dados é realizada por meio de visita, entrevistas, análise documental, participação em reuniões de planejamento, conselhos de classe e encontros de formação pedagógica, bem como a observação do cotidiano de uma sala de aula dos anos finais do ensino fundamental, do ensino médio ou de educação 
de jovens e adultos. Para essa atividade convergem os conteúdos dos componentes curriculares Psicologia da Educação, Políticas da Educação, Didática, Antropologia das Sociedades Indígenas e Afrodescendentes, Educação e Direitos Humanos e Educação do Campo.

A terceira fase do estágio - com duração de 56 horas - ocorre no $6^{\circ}$ semestre com atividades de monitoria em cursos da área agrícola dos anos finais do ensino fundamental, ensino médio, ou na educação de jovens e adultos, tendo como atividades 8 horas de observação e 16 horas de monitoria realizada em quatro componentes curriculares do curso escolhido, atividades de planejamento e de intervenção de 2 horas. Para a elaboração dessa atividade convergem todos os componentes curriculares cursados até o $6^{\circ}$ semestre.

Os Estágios Supervisionados IV e o V, que fazem parte da matriz curricular no $7^{\circ}$ e $8^{\circ}$ semestres, têm duração de 120 horas cada um e destinam-se à realização da docência na educação profissional nas áreas da Produção Animal e Produção Agroindustrial (Estágio IV) e Produção Vegetal e Infraestrutura Agrícola (Estágio V). Em cada etapa deve ser realizada a observação (8 horas em cada componente curricular das duas áreas), elaborado o planejamento das aulas e do material didático, a realização da regência (20 horas em cada componente curricular), bem como a elaboração de relatório.

Os campos de estágio são as escolas agrícolas conveniadas que se localizam na região de abrangência do Campus e que pertencem à Rede Estadual de Educação do Rio Grande do Sul, além dos cursos do próprio Campus Sertão, já que nele estudam onze turmas no curso Técnico em Agropecuária integrado e uma turma subsequente.

Cada um desses componentes curriculares é coordenado por um docente da área pedagógica e na fase de regência (Estágios Supervisionados IV e V) também há a participação de um professor de cada área específica do curso (Produção Animal, Produção Vegetal, Produção Agroindustrial e Infraestrutura Agrícola). As etapas são concluídas com a produção de relatórios e a na finalização do processo ocorre a apresentação das atividades para banca formada pelos docentes responsáveis pela coordenação dos estágios e convidados das áreas específicas. 
Ao longo dessa trajetória os licenciando tentam articular os conteúdos estudados nos componentes curriculares das áreas pedagógica e de formação específica e ao se defrontarem com a prática docente percebem a necessidade de adotar estratégias de ensino diversas das que vivenciam como alunos da graduação, já que realizam o estágio na educação básica, o que exige o planejamento e organização em suas ações e contribui para a sua formação docente.

\subsection{O curso de Formação Pedagógica para Docentes da Educação Básica e Profissional e o estágio supervisionado}

O curso de Formação Pedagógica para Docentes da Educação Básica e Profissional foi criado segundo as regras do Programa Especial definido pela Resolução CNE/CEB ํo 02/97 em 2010, porém é considerado curso regular, avaliado pelo Ministério da Educação.

Nele, até o momento, ingressaram dez turmas, das quais oito já o concluíram, o que the confere regularidade, diferenciando-o dos programas emergenciais. Em 2010, foram ofertadas setenta vagas, e, após aquele ano são quarenta vagas anuais e em 2018 há sessenta e sete alunos matriculados, oriundos de cidades do Rio Grande do Sul e oeste de Santa Catarina.

O curso teve por objetivo inicial qualificar os professores que atuam na instituição ofertante, porém passou a atender profissionais ligados a outras instituições de EP da sua área de abrangência, conforme estabeleceu a Resolução CNE/CEB o 02/97, art. 1ำ, parágrafo único. O curso, portanto, é uma complementação à graduação, em áreas em que não há o oferecimento regular de licenciaturas tendo como objetivo a extensão dos conhecimentos, a qualificação e/ou aperfeiçoamento dos profissionais graduados para o exercício do magistério.

Ele ocorre em regime especial, com aulas nos fins de semana (sexta-feira noturno e sábado diurno) e tem carga horária de 956 horas. Considerando as normativas legais (Resolução CNE/CEB no 02/97 e Resolução no 02/2015) que disciplinam a oferta dessa modalidade de curso (em forma de programa) sua organização curricular se estrutura em núcleos: 
a) Núcleo I - estudos de formação geral, das áreas específicas e interdisciplinares, e do campo educacional, seus fundamentos e metodologias, e das diversas realidades educacionais;

b) Núcleo II - aprofundamento e diversificação de estudos das áreas de atuação profissional, incluindo os conteúdos específicos e pedagógicos, priorizadas pelo projeto pedagógico das instituições, em sintonia com o sistema de ensino.

c) Núcleo III - estudos integradores para enriquecimento curricular, que é constituído pelas atividades teórico-práticas que visam fornecer flexibilidade ao programa, estimulando a discussão de temas emergentes no cenário educacional e não contemplados no currículo.

A parte prática ocorre por meio de estágio supervisionado de 400 horas que é realizado em instituições de ensino que oferecem cursos de EP, inclusive na própria instituição em seus cursos de nível médio (Técnico em Agropecuária, Técnico em Comércio - PROEJA e Técnico em Manutenção e Suporte em Informática Integrado e Concomitância Externa). Os componentes pedagógicos totalizam 416 horas e mais 40 horas de atividade curricular complementar.

O estudante inicia o Estágio Supervisionado no segundo semestre do curso e os estágios posteriores após a conclusão do primeiro, já que esses componentes curriculares possuem pré-requisitos. Eles são coordenados pelo coordenador do curso que fornece as orientações gerais (normas relativas ao estágio, campos de estágio, atividades a serem desenvolvidas, modelos de relatórios, documentações relativas aos campos de estágio), encaminhamento dos estudantes aos professores orientadores e participação nas bancas de socialização das atividades do estágio.

Os professores orientadores são docentes que ministram os demais componentes curriculares do curso, sendo que cada um deles orienta em torno de seis estudantes aos quais prestam assessoramento no que se refere à elaboração e desenvolvimento das atividades de estágio, esclarecendo dúvidas, supervisionando as atividades desenvolvidas, registrando as frequências e avaliação e participando nas bancas de socialização das atividades do estágio.

Além desses profissionais também atua no estágio o professor responsável pelo campo de estágio, que tem por função recepcionar o estudante, viabilizar o 
acesso às informações necessárias à realização das atividades, aprovar o plano de estágio e acompanhar a sua execução em sala de aula e participar da sua avaliação.

O Estágio Supervisionado está organizado em três etapas. No Estágio Supervisionado I o estagiário opta por uma instituição de educação básica que oferece curso técnico de nível médio onde deverá observar e analisar a organização e o funcionamento da instituição, coletando dados por meio de análise documental, entrevistas, conversas informais, visitas e observações. Também deverá aprofundar a análise da dimensão pedagógica por meio de observações das aulas de um componente curricular e realização de entrevista com o professor. Os dados são analisados tomando como referência as contribuições dos componentes curriculares ofertados no primeiro e segundo semestres do curso, quais sejam:

- História da Educação Profissional, Legislação Profissional, Sociologia da Educação, Filosofia da Educação e Tecnologias da Informação e Comunicação na Educação: fornecem os subsídios para a análise da organização e funcionamento geral da instituição, como histórico, caracterização do alunado, cursos ofertados, condições físicas, gestão financeira, administrativa e pedagógica, etc;

- Teorias do currículo: análise da composição do currículo do curso técnico tomando como referência os estudos teóricos e as normativas legais;

- Psicologia da Educação: análise das abordagens que norteiam o processo ensino-aprendizagem observado na instituição;

- Didática: análise da organização do processo pedagógico que se efetiva na sala de aula: objetivos, conteúdos, metodologia, recursos didáticos, avaliação, etc.

- Educação inclusiva e Antropologia das Sociedades Indígenas e Afrodescendentes no Brasil: análise das condições institucionais em que se efetiva inclusão de pessoas com deficiência e/ou outras singularidades/diversidade.

Os resultados do trabalho - aspectos observados e sua análise crítica - são debatidos com a turma e professores orientadores em seminário interno, atentando para o que defendem Pimenta; Lima (2009, p.43) acerca do papel das teorias, que é o de [...] iluminar e oferecer esquemas para análise e investigação que permitam questionar as práticas institucionalizadas e ações dos sujeitos e, ao mesmo tempo, colocar elas próprias em questionamento, uma vez que as teorias são explicações sempre provisórias da realidade. 
No Estágio Supervisionado II o estudante deve, na primeira etapa, observar no mínimo oito horas-aula de um componente curricular de curso técnico de sua área de formação e elaborar, sob a orientação do professor orientador, o relatório de observação. Na segunda etapa elabora o planejamento do estágio de docência e o material didático, subsidiado pelos componentes curriculares Didática e Metodologia do Ensino da Educação Profissional, sob orientação do professor orientador e do professor do campo de estágio responsável pelo componente curricular no curso técnico.

Por fim, no Estágio Supervisionado III o estudante desenvolve a regência por um período de 32 horas, sob a supervisão do professor responsável pelo campo de estágio e acompanhamento do professor orientador e elabora o relatório final das atividades de estágio que é apresentado em banca.

Essa forma de organização do estágio tem por objetivo articular os aspectos observados nos campos de estágio com os conteúdos ministrados no curso, de modo que, como recomendam Pimenta; Lima (2009, p. 54):

O estágio, então, deixa de ser considerado apenas um dos componentes e mesmo um apêndice do currículo e passa a integrar o corpo de conhecimentos do curso de formação de professores. Poderá permear todas as suas disciplinas, além de seu espaço específico de análise e síntese ao final do curso. Cabe-lhe desenvolver atividades que possibilitem o conhecimento, a análise, a reflexão do trabalho docente, das ações docentes, nas instituições, a fim de compreendê-las em sua historicidade, identificar seus resultados, os impasses que apresenta, as dificuldades. Dessa análise crítica, à luz dos saberes disciplinares, é possível apontar as transformações necessárias no trabalho docente, nas instituições.

Assim, o estágio supervisionado pode se constituir num importante momento para a construção dos saberes docentes se, inserindo-se no campo do exercício profissional, o licenciando consiga articular os conteúdos e práticas da formação com os requeridos pela profissão, vivenciando a indissociabilidade entre teoria e prática.

\section{CONSIDERAÇÕES FINAIS}


O objetivo central do estágio supervisionado é contribuir para a construção dos saberes requeridos no exercício da docência e as produções acadêmicas sobre o tema que analisamos indica que há unanimidade entre os autores sobre a importância dessa etapa da formação profissional.

Os dados também permitem constatar que a universidade não é mais o único lócus de formação de professores, já que os Institutos Federais de Educação, Ciência e Tecnologia têm ampliado as oportunidades de ingresso nas licenciaturas, especialmente as da área de ciências naturais, conforme dispõe a legislação que os criou.

O mesmo não se pode afirmar em relação aos cursos de formação dos professores para atuação nos componentes curriculares das áreas profissionalizantes, já que foram localizados poucos trabalhos em cursos dessa natureza. Da mesma forma, é limitado o número de produções que tomaram como tema central os estágios supervisionados nesses cursos. Assim, ficam algumas indagações: Os IFEs não tem cumprido seu papel de formar esses profissionais? Não estão ocorrendo experiências de oferta de Programas de Formação Pedagógica para esses docentes? Os professores que atuam nos cursos de licenciatura/Programas de Formação Pedagógica não têm produzido trabalhos a respeito do estágio supervisionado que neles se efetivam? A seleção dos trabalhos analisados nesse texto não é representativa, uma vez que pode haver trabalhos sobre o tema que não foram por nós localizamos? Essas são questões que ainda demandam aprofundamento.

Visando contribuir para a ampliação das informações sobre o tema, mesmo sem adentrar a uma reflexão mais consistente, relatamos a forma de organização e funcionamento dos estágios supervisionados em dois cursos de formação de professores para a área técnica da educação profissional oferecidos pelo Instituto Federal de Educação, Ciência e Tecnologia do Rio Grande do Sul - Campus Sertão, esperando que ele possa subsidiar outras práticas e gerar debates sobre esse importante tema relativo à formação profissional.

\section{REFERÊNCIAS}

ALMEIDA, M.I.; P., S.G. Estágios supervisionados na formação docente. São Paulo: Cortez, 2014.

BRASIL. MEC/INEP. Sinopse estatística da educação básica 2017. Brasília:

MEC/INEP, 2017. Disponível em: http://portal.inep.gov.br/sinopses-estatisticas-daeducacao-basica. Acesso em: 12.jun.2018.

CANÁRIO, R. A prática profissional na formação de professores. In: CAMPOS, Bártolo Paiva. Formação profissional de professores no ensino superior. Porto: Porto Editora, 2001. 
FORMOSINHO, J. A formação prática de professores. In: CAMPOS, Bártolo Paiva. Formação profissional de professores no ensino superior. Porto: Porto Editora, 2001, p. 46-64.

KULCSAR, R. O estágio supervisionado como atividade integradora. In: PICONEZ, S.C. B. (Coord.) A prática de ensino e o estágio supervisionado. 24. ed. Campinas: Papirus, 2012, p. 57-67.

MARTINS, P.A.; NASCIMENTO, A.S. G.; SOUZA, F.C. S. Licenciaturas nos institutos federais: a produção acadêmica sobre o estágio supervisionado. Revista de Iniciação Científica da ULBRA. Canoas, n.13, p. 149 - 155, 2015.

OLIVEIRA, B. M.; OLIVEIRA; M. R. N. S. Licenciaturas nos institutos federais: aspectos para discussão. Revista Brasileira da Educação Profissional Tecnológica, Natal (RN), v.10, n. 10, p. 22-33, 2016.

PICONEZ, S.C. B. Prática de ensino e o estágio supervisionado: a aproximação da realidade escolar e a prática da reflexão. In: (Coord.) A prática de ensino e o estágio supervisionado. 24. ed. Campinas: Papirus, 2012. p. 13-33.

PIMENTA, S. G. O estágio na formação de professores: unidade teoria e prática? 10. ed. São Paulo: Cortez, 2011.

PIMENTA, S.G.; LIMA, M.S.L. Estágio e docência. 4. ed. São Paulo: Cortez, 2009.

PIMENTA, S.G.; LIMA, M.S.L. Estágio e docência: diferentes concepções. Revista Poíesis. v.3, n. 3 e 4, p. 5 -24, 2005/2006.

TARDIF, M. Saberes docentes e formação profissional. 7. ed. Petrópolis: Vozes, 2002.

\section{ANEXO}

Quadro 1 - Produções sobre estágio supervisionado

\begin{tabular}{|l|l|}
\hline \multicolumn{1}{|c|}{ Autor/es } & \multicolumn{1}{c|}{ Título do trabalho } \\
\hline LAPA, B.C.; AZEVEDO, & $\begin{array}{l}\text { A constituição do processo identitário de professores de } \\
\text { ciências no estágio curricular supervisionado. }\end{array}$ \\
\hline R.O.M. & $\begin{array}{l}\text { A formação de professores e os currículos das licenciatura } \\
\text { s dos Institutos Federais de Educação, Ciência e Tecnolog } \\
\text { ia. }\end{array}$ \\
\hline $\begin{array}{l}\text { LAMB,M.E.; } \\
\text { AN, A. }\end{array}$ & A formação prática de professores no estágio curricular. \\
\hline $\begin{array}{l}\text { FELICIO, H.M.S; OLIVEIRA, } \\
\text { R.A. }\end{array}$ & $\begin{array}{l}\text { A importância da prática do estágio supervisionado nas } \\
\text { licenciaturas. }\end{array}$ \\
\hline $\begin{array}{l}\text { SCALABRIN, I.C; } \\
\text { MOLINARI, A.M.C. }\end{array}$ & A importância do estágio na formação de professores. \\
\hline $\begin{array}{l}\text { CHAVES, I.C.G.; } \\
\text { RODRIGUES, J.S.; SILVA, } \\
\text { A.P.B. }\end{array}$ & $\begin{array}{l}\text { A importância do estágio supervisionado na formação do } \\
\text { profissional de educação física: uma visão docente e } \\
\text { discente. }\end{array}$ \\
\hline $\begin{array}{l}\text { SOUZA, J.C.A; BONELA, } \\
\text { L.A. }\end{array}$ & $\begin{array}{l}\text { A prática como componente curricular na representação } \\
\text { dos estudantes de licenciatura em matemática: entre o } \\
\text { dito e o feito. }\end{array}$ \\
\hline $\begin{array}{l}\text { HOEPERS, I.S.; } \\
\text { FERNANDES, S. R.S. }\end{array}$ & $\begin{array}{l}\text { A prática do estágio: uma contribuição para a construção } \\
\text { da identidade profissional docente. }\end{array}$ \\
\hline $\begin{array}{l}\text { OLIVEIRA, L.S.; SANTOS, } \\
\text { S.A.; SANTOS, M.C.O.; } \\
\text { MARQUES, Â.M. }\end{array}$ & \\
\hline
\end{tabular}




\begin{tabular}{|c|c|}
\hline $\begin{array}{l}\text { MARTINS, P.A.S.; } \\
\text { NASCIMENTO, A.S.G.; } \\
\text { SOUZA, F.C.S. }\end{array}$ & $\begin{array}{l}\text { Licenciaturas nos institutos federais: a produção } \\
\text { acadêmica sobre o estágio supervisionado. }\end{array}$ \\
\hline $\begin{array}{l}\text { IELLO, S.P.T.; LINDNER, } \\
\text { M.T. }\end{array}$ & $\begin{array}{l}\text { A contribuição dos estágios na formação docente: } \\
\text { observações de alunos e professores. }\end{array}$ \\
\hline $\begin{array}{l}\text { IMA, G.B.V.; SANTOS; } \\
\text { I.L.B. }\end{array}$ & $\begin{array}{l}\text { Contribuição do estágio supervisionado para formação do } \\
\text { futuro professor no curso de licenciatura em química do } \\
\text { IFPB. }\end{array}$ \\
\hline $\begin{array}{l}\text { ILVA, K.L.S.; SILVA, } \\
\text {.H.S.; SILVA, P.M.L.; } \\
\text { LIVEIRA, E.S; SOUZA, } \\
\text {.P.; MELO, R.F. }\end{array}$ & $\begin{array}{l}\text { Desafios do estágio supervisionado para a formação } \\
\text { docente no curso de licenciatura em computação. }\end{array}$ \\
\hline $\begin{array}{l}\text { IMENTA, S.G.; LIMA, } \\
\text { I.S.L. }\end{array}$ & Estágio e docência: diferentes concepções. \\
\hline $\begin{array}{l}\text { JETA, M.P.S; ANDRADE, } \\
\text { M. }\end{array}$ & $\begin{array}{l}\text { Estágio em geografia: teoria e prática na formação de } \\
\text { professores. }\end{array}$ \\
\hline $\begin{array}{l}\text { SANTOS, J; AZEVEDO, } \\
\text { R.O.M. }\end{array}$ & $\begin{array}{l}\text { Estágio supervisionado no ensino médio: uma experiência } \\
\text { na educação profissional tecnológica. }\end{array}$ \\
\hline $\begin{array}{l}\text { FALONE, S.Z.; MEDEIROS, } \\
\text { J.; OLIVEIRA, S.M. }\end{array}$ & $\begin{array}{l}\text { Estágio-pesquisa na formação de professores no Instituto } \\
\text { Federal Goiano. }\end{array}$ \\
\hline LMEIDA, L.S. & $\begin{array}{l}\text { Formação inicial de professores de física no } \\
\text { IFRN/Campus Caicó: o estágio docente em perspectiva. }\end{array}$ \\
\hline $\begin{array}{l}\text { ERNARDY, K.; PAZ, } \\
\text { M.T. }\end{array}$ & $\begin{array}{l}\text { Importância do estágio supervisionado para a formação de } \\
\text { professores. }\end{array}$ \\
\hline ARAÚJO, K.C.L.C. & $\begin{array}{l}\text { O debate da política curricular e os sentidos do estágio } \\
\text { supervisionado (1996-2006): uma análise a partir da teoria } \\
\text { do discurso. }\end{array}$ \\
\hline $\begin{array}{l}\text { DALLA CORTE, A.C.; } \\
\text { LEMKE, C. K. }\end{array}$ & $\begin{array}{l}\text { O estágio supervisionado e sua importância para a } \\
\text { formação docente frente aos novos desafios de ensinar. }\end{array}$ \\
\hline LIMA, L.S. & $\begin{array}{l}\text { O estágio supervisionado na formação do professor } \\
\text { reflexivo - concepções do aluno-estagiário. }\end{array}$ \\
\hline $\begin{array}{l}\text { BALDOINO, L. .M.; FELICIO, } \\
\text { C.M. }\end{array}$ & $\begin{array}{l}\text { O estágio, a legislação e as expectativas dos estudantes } \\
\text { de licenciatura do Ifgoiano Campus Morrinhos. }\end{array}$ \\
\hline $\begin{array}{l}\text { PINHEIRO, T.S.; TEIXEIRA, } \\
\text { C.B.; VIEIRA, M.D.S.; }\end{array}$ & $\begin{array}{l}\text { O papel do estágio na formação de professores: as } \\
\text { contribuições para a formação na diversidade. }\end{array}$ \\
\hline $\begin{array}{l}\text { ROCHA, K.M.R.; ABBEG, I.; } \\
\text { RELA, E. }\end{array}$ & $\begin{array}{l}\text { Orientação de estágio: uma experiência na formação de } \\
\text { docentes. }\end{array}$ \\
\hline DAVANÇO, V.H. & O espaço do estágio na formação docente. \\
\hline FELDKERCHER, N. & $\begin{array}{l}\text { O estágio curricular supervisionado como componente } \\
\text { teórico e prático em cursos de formação inicial de } \\
\text { professores. }\end{array}$ \\
\hline MELO, M. C. G. & $\begin{array}{l}\text { O estágio curricular supervisionado na formação docente: } \\
\text { uma vivência indispensável. }\end{array}$ \\
\hline PIMENTA, S.G. & $\begin{array}{l}\text { O estágio na formação de professores: unidade teoria e } \\
\text { prática? }\end{array}$ \\
\hline BONETTO, L.R.; WELTI & $\begin{array}{l}\text { Reflexões sobre a atuação docente em estágio realizado } \\
\text { em instituição da rede federal de educação tecnológica. }\end{array}$ \\
\hline PEREIRA, H.M.R.; & $\begin{array}{l}\text { Uma reflexão acerca do estágio supervisionado na } \\
\text { formação dos professores de ciências biológicas. }\end{array}$ \\
\hline
\end{tabular}

